\section{Reignite your career development}

If you're looking to reignite your passion for dentistry and give your career a new lease of life, consider the PG Cert in Implant Dentistry delivered through Ucer Education.

This 12-month, multi-system, blended learning course provides a level 7 award by EduQual. It covers both theoretical and practical modules and offers structured mentoring to provide a comprehensive foundation in dental implantology.

Led by Specialist Oral Surgeon, Professor Cemal Ucer, and his leading teaching faculty based at the ICE Postgraduate

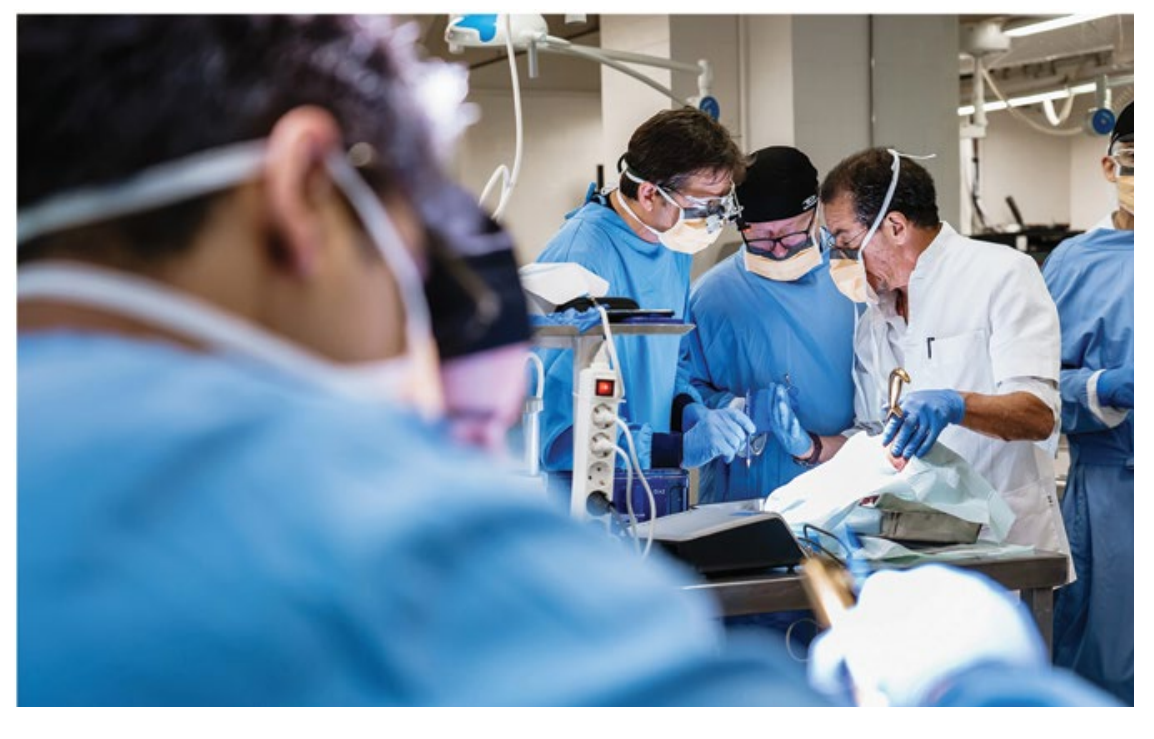

\section{A superior level of protection}

If you are looking for reliable solutions that deliver a superior level of protection for you and your patients, you can have complete confidence in Nuview.
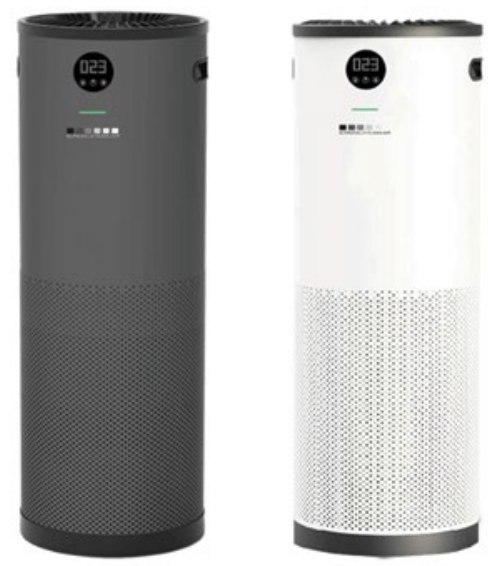

Training Institute in Manchester, the training is supplemented by state-of-the-art facilities, including full digital workflow and surgical navigation techniques.

The next cohort starts in November 2020, visit the website to find out more.

For more information on the PG Cert in Implant Dentistry from Ucer Education supported by Geistlich, Megagen, Neoss, TRI Implants and General Medical - visit www.ucer.education, call Prof Ucer on 0161237 1842, or email ucer@oralimplants.com. multi-stage air purifying technologies to effectively and quietly clean and purify indoor air for hourly air changes

- The Uvex visor for comfortable personal protection with unmatched optical quality

- Zeiss Microscope drapes, which include the VisionGuard lens protection system.

For total protection, trust in Nuview. For more information please call Nuview on 01453 872266, email info@nuview-ltd. Facebook.

\section{A beautiful and safe dental chair}

Having taken the decision to invest in a Belmont treatment centre you will want to ensure it stays looking good. This will involve taking care of the upholstery, and for this Belmont have given practices a helping hand. Their upholstery is designed to ensure the rigorous demands of a healthcare environment. The meticulous Japanese manufacturing process achieves both strength and longevity, making their fabrics naturally antimicrobial as well as ink and stain resistant.

Aesthetics must be matched with functionality, particularly in the current environment. Belmont has recently launched a range of care products which ensures the safety as well as the aesthetics of their equipment. There are two products in the chair maintenance range - B100 \& B300. Chairs need to be wiped down between patients and for such regular use you need a fast-acting upholstery cleaner that will not damage artificial leather; B300 does just that. It has reduced levels of alcohol so that over time it will prevent brittle, cracked surfaces. More importantly, it fulfils European virucidal standards and is effective against all enveloped viruses as well as the new type of coronavirus (SARS-CoV-2).

The perfect adjunct to this is $\mathrm{B} 100$, an intensive cleaner designed for occasional use, to remove stains of all kinds as well as discoloration. Despite its rigorous cleaning action, it will not damage your upholstery. In conjunction with B300, it will keep your chair looking beautiful as well as safe in the new environment in which practices now find themselves working. com, visit www.nuview.co or 'like' Nuview on 